DOI: 10.20472/IAC.2018.036.041

\author{
LYN RAGSDALE \\ Rice University, United States
}

\title{
THE AMERICAN NONVOTER
}

\begin{abstract}
:
This paper examines the motivations of individuals who do not vote in American elections from 1968 through 2012. Existing research portrays American nonvoters as a large monolith of people who lack psychological involvement in politics, do not have adequate personal resources to participate, have insufficient social networks to be engaged, or are not sufficiently mobilized by candidates and campaigns. Instead, our paper maintains that uncertainty in the national campaign context -the economic, mass communication, legal, and international environments--drives individual citizens' decisions about whether to vote. When there is high uncertainty in the national campaign context, people are more likely to vote. When there is low uncertainty in the national campaign context, citizens are less likely to vote. The paper further develops a theoretical distinction between the external uncertainty found in the national campaign context and the internal uncertainty citizens feel about which candidate will adequately address the external uncertainty. In considering this internal uncertainty, four types of nonvoters emerge as they respond differently to the lack of clarity. First, the politically ignorant non-voters do not follow the campaign or the candidates so avoid internal uncertainty about them. Second, the indifferent follow the campaign and the candidates, but see no differences between the candidates, leaving internal uncertainty about them.

Third, the dissatisfied know a good deal about the campaign context and the candidates but see one or more candidates negatively. They too do not vote because internal uncertainty about the candidates remains unresolved. Finally, the personal hardship nonvoters pay attention to the campaign and the candidates but do not vote because of personal hardship associated with unemployment. The paper first considers broad differences between voters and nonvoters in their knowledge of politics and attitudes toward elections. It then estimates a model of nonvoting across the time period. Finally, it considers in greater detail the four different types of nonvoters, who they are, and what motivates them not to participate. The study finds that at the presidential level, there are considerable numbers of dissatisfied nonvoters who do not vote because they have negative views of one or both candidates. At the midterm level, nonvoters are more likely to be politically indifferent, not having clear-cut views of one or both candidates.
\end{abstract}

\section{Keywords:}

nonvoter, United States, negative campaigns 